\title{
Overload Mitigation SIPS Based on DC Model Optimization and PMU Technology
}

\author{
Zoran ZBUNJAK, Igor KUZLE, Dino MAĐAR
}

\begin{abstract}
System integrity protection schemes (SIPS) supported by phasor measurement unit (PMU) technology are based on the concept of collecting information from remote stations, sending the information to a central concentrator that executes a decision-making algorithm and initiates specialized actions to prevent the spread of system disturbance. This paper gives application of overload mitigation SIPS. Described protection scheme is based on a mixed integer linear programming (MILP) optimization of the DC power flow model whose objective is to maximize total load on the observed part of the network. Inaccuracy of the used DC model and the actual state is replaced by using the PMU technology. In this way, the influence of reactive power that is ignored in the DC model power flow model calculation is replaced in real-time with real synchronized measurements. Described SIPS is tested on IEEE 14 busbar test system. Conducted simulations indicate that developed optimization algorithm can mitigate potential element overloads with extremely high accuracy by using load shedding methods. Example on real part of Croatian power transmission network is given at the end of paper. This specific analysis demonstrates benefits of using SIPS based on synchro phasors in real world.
\end{abstract}

Keywords: optimization; overload mitigation; phasor measurement unit; system integrity protection scheme

\section{INTRODUCTION}

Electric power system (EPS) protection based on advanced technologies enables system integrity and safe operation in conditions of compromised or questionable security [1]. Power transmission system advanced control implies joint advanced performance based on the control, protection and measurement functions. Every defined operation needs to work in real-time with very safe and reliable use of telecommunication network and extreme speed requirements [2]. One of technologies that can support development of advanced control system is PMU technology. This technology has been developed in the 1980s [3] and can be used in many applications like e.g. power system state estimation described in [4]. Advanced control and SIPS are specific areas where significant improvements can be achieved using PMU technology according to [5].

The cause of power systems blackouts, especially large and rare interruptions in electricity supply, is usually a combination of a series of mutually connected events. Such a combination is very unlikely, but sometimes not a low risk, and it involves chain of a large number of cascade events [6].

Protection schemes are based on the concept of collecting information from remote stations, sending the information to a central unit that executes a decision-making algorithm and initiates specialized actions to prevent the spread of system disturbance. Fig. 1 shows SIPS supported by PMU technology.

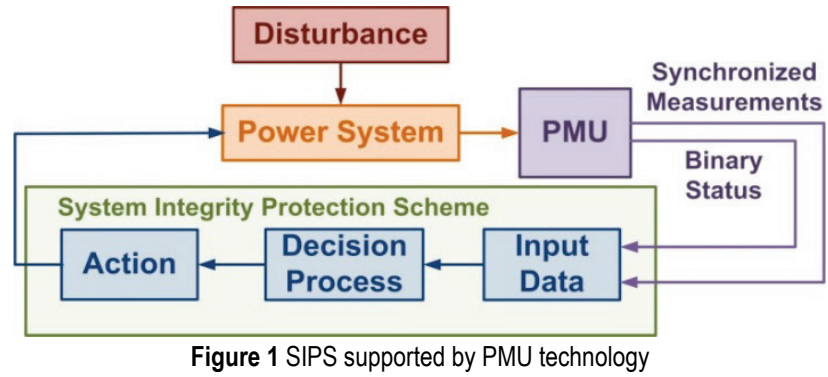

Special protection schemes are defined in [7] as schemes designed to identify special events that cause unusual problems in the power system operation and take advanced predefined measures to neutralize recorded events.

In 2010 a report on SIPS was published [8]. According to report the SIPS deal with congestion, thermal overload, voltage, frequency and angular instability problems. Stated problems can be mitigated using different types of protection schemes. Load shedding schemes together with overload and congestion mitigation schemes are studied within this paper.

Undertaken research within the presented paper refers to congestions in parts of the power transmission network due to the electricity market conditions of its controlling [9].

One of synchronized measurement application for reducing excessive standing phase angle difference is given in paper [10]. Generation control method for reducing phase angle differences is described in order to bring system back to normal condition.

Deployment of wide area monitoring, protection and control (WAMPAC) systems is recognized as one of important goals in future Great Britain power system [11]. With future research, wide area oscillation control in Great Britain power system should be developed using the synchronized measurements technology.

This paper gives application of overload mitigation protection scheme. Described protection scheme is based on MILP optimization of the DC power flow model whose objective is to maximize total load on the observed part of the network. Inaccuracy of the used DC model and the actual state is replaced by using the PMU technology. In this way, the influence of reactive power, that is ignored in the DC model power flow model calculation, is replaced in real-time with real synchronized measurements.

A detailed mathematical description of used optimization algorithm is given in chapter 2 .

Chapter 3 presents operation analysis of the described protection scheme on the IEEE 14 busbar test system.

Application of protection scheme on the real part of the Croatian transmission system, subsystem Istria, is shown in chapter 4 after verifying scheme on IEEE test system.

The contribution of this paper is the use of PMU technology to measure the actual loads of the monitored part of the network in order to determine in real time the difference in the loads imposed by the assumptions set when 
using the DC power flow model in relation to the actual power flows.

\section{MILP BASED ON DC POWER FLOW MODEL}

The task of the optimization algorithm is to mitigate the overload in the network by optimizing consumption with the aim of preserving the transmission system. The algorithm applies MILP based on the method of branching and fencing.

MILP studies the optimization problems within the system's default limits. Optimization can be based on the problem of maximizing or minimizing the default objective function by finding appropriate decision variables along with the constraints described by certain equations and inequalities. At MILP, a certain decision variable can take values from a set of real or integer numbers. The method of branching and fencing is based on the principle of successive solving the objective function, while the permissible values of the decision variables do not reach the optimal solution. The details of the integer programming can be found in [12].

The mathematical model of used algorithm is based on the power flow calculation of the simplified model of the network, the so-called DC model. The DC model assumes three assumptions:

- line resistance $R_{L}$ is negligible in relation to line reactance $X_{L}$,

$R_{L} \ll X_{L}$

- $\quad$ per unit voltage $\left|V_{N}\right|$ is the same for all nodes,

$\left|V_{N}\right|=1 p . u$.

voltage angles difference $\delta_{i}-\delta_{j}$ of the adjacent nodes is small, which derives:

$\sin \left(\delta_{i}-\delta_{j}\right) \approx\left(\delta_{i}-\delta_{j}\right) ; \cos \left(\delta_{i}-\delta_{j}\right) \approx 1$

Obviously, taking into account these assumptions affects the accuracy of the DC model. According to [13], the total error of the DC model is 5\% compared to the more accurate AC nonlinear model. Though the accuracy of the DC model is smaller than the AC model, it is characterized by the simplicity and the speed of the calculation conditioned by its linearity, which is why it is proposed in making SIPS.

\subsection{Mathematical Model}

Power flow calculation for DC network model is based on the following expression:

$P_{i j}=\left(\frac{\delta_{i}-\delta_{j}}{X_{i j}}\right) \cdot T_{i j} ; \quad i, j \in N ; \delta_{R E F}=0$

where: $i, j$ - node tags; $P_{i j}$ - active power flow from node $i$ to node $j ; \delta_{i}, \delta_{j}$ - voltage phase angle for node $i$ and $j ; X_{i j}$ element reactance between nodes $i$ and $j$; $T_{i j}$ - element connection between nodes $i$ and $j$, defined as binary value
0 for disconnected or 1 for connected state; $N$ - number of nodes; $\delta_{R E F}$ - reference voltage phase angle.

The node sum is defined by the following expression:

$$
V A R_{i} \cdot L_{i}=G_{i}+\sum_{j \in N} P_{i j} ; i, j \in N
$$

where: $V A R_{i}$ - load shedding solution at node $i$, defined as binary value 0 for load disconnection or 1 for load connection at node $i ; L_{i}$ - active load power at node $i$ in MW; $G_{i}$ - active generation power at node $i$ in MW.

Real-time adjustment factor $k_{Q}$ is created in order to compensate inaccuracy of the DC model. It represents impact of reactive power in the real system relative to its neglect in the DC model.

$P_{i j} \leq k_{Q} \cdot S_{i j M A X} ; i, j \in N$

where: $k_{Q}$ - adjustment factor that is calculated in real time when overloading occurs in MW/MVA according to Eq. (7); $S_{i j M A X}$ - maximum transmission power between nodes $i$ and $j$ in MVA.

Adjustment factor is calculated in real time when overloading occurs in MW/MVA according to Eq. (7), and its value is always less than 1 .

$k_{Q}=\frac{P_{i j D C}}{S_{i j R E A L}} ; i, j \in N ; k_{Q}<1$

where: $P_{i j D C}$ - calculated active power flow based on the DC model from node $i$ to node $j$ when overloading occurs; $S_{i j R E A L}$ - real time measured apparent power of the overloaded connection between node $i$ and node $j$ when overloading occurs.

As an additional release condition the model allows definition of critical loads which must remain connected according to Eq. (8).

$$
V A R_{i} \geq \text { PRIOR }_{i} ; \quad i \in N
$$

where: $P R I O R_{i}$ - load shedding release condition in node $i$, defined as binary value 0 for loads that can be disconnected or 1 for loads that must remain connected.

Objective function is to maximize connected load according to Eq. (9).

$$
\operatorname{Max}\left(\sum_{i \in N} V A R_{i} \cdot L_{i}\right)
$$

Defined mathematical model finds a combination of loads whose total real time measured sum represents maximum possible load due to the constraints of transmission power capacity of all connections in the real time topology of the transmission network.

Block diagram of proposed optimization algorithm is given in Fig. 2. 


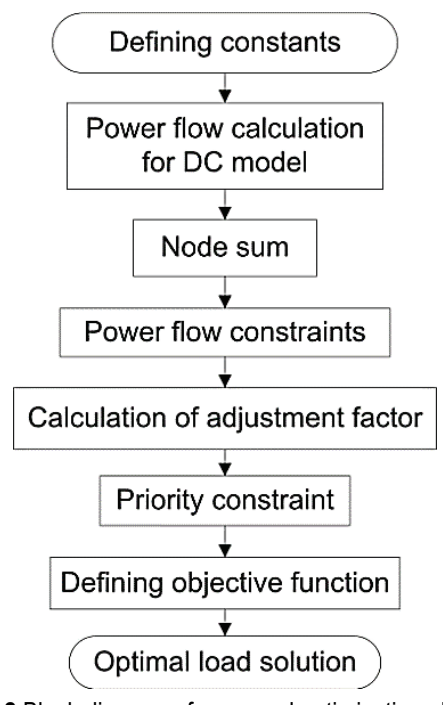

Figure 2 Block diagram of proposed optimization algorithm

\section{STUDY CASE ON IEEE 14 BUSBAR TEST SYSTEM}

Universality of described SIPS is verified on the IEEE 14 busbar test system, Fig. 3. Data for IEEE 14 busbar test system were downloaded from the University of Washington test case archive [14]. Rated power of lines and transformers is assumed in Tab. 1. because the standard IEEE 14 busbar test system does not define the specified values. PMU placement method is based on the complete system observability that results in PMUs placement in each node that has modelled load or generator. In addition to the described nodes, PMUs are also placed on endangered network elements.

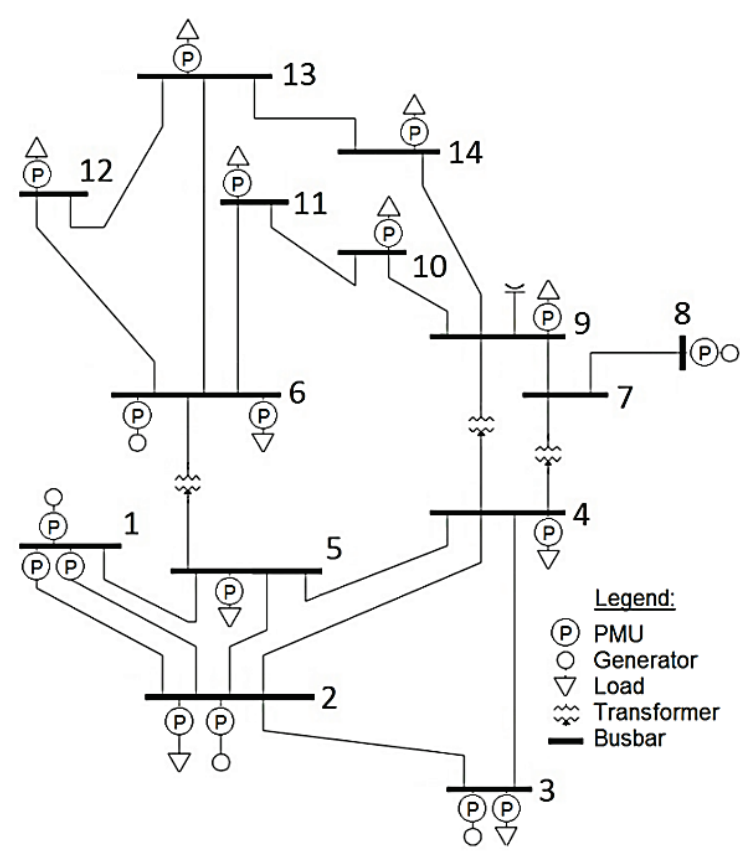

Figure 3 IEEE 14 busbar test system with PMUs placement
Table 1 Assumed rated power of lines and transformers

\begin{tabular}{|c|c|}
\hline Elements & $\begin{array}{c}\text { Rated power } \\
\text { (MVA) }\end{array}$ \\
\hline $\begin{array}{c}\text { Lines } \\
1-2(1), 1-2(2), 1-5, \\
2-3,2-4,2-5,3-4,4-5\end{array}$ & 130 \\
\hline $\begin{array}{c}\text { Transformers } \\
4-7,4-9,5-6\end{array}$ & 85 \\
\hline $\begin{array}{c}\text { Lines } \\
6-11,6-12,6-13,7-8,7-9, \\
9-10,9-14,10-11,12-13,13-14\end{array}$ \\
\hline
\end{tabular}

\subsection{Base Case Scenario}

Power flow calculation was carried out without any change to default scenario using a nonlinear $\mathrm{AC}$ model in the PSS/E software. IEEE 14 busbar test system is characterized by the majority of generation in busbar 1 and a smaller part in busbar 2. Synchronous compensators that maintain voltage in the analysed model are modelled in busbars 3,6 and 8 .

\section{$3.2 \mathrm{~N}-1$ Analysis}

$\mathrm{N}-1$ analysis of IEEE 14 busbar test system including assumed rated power of lines and transformers indicated a situation where N-1 criterion was not satisfied. Outage of one of lines 1-2 with assumed rated power of 130 MVA causes overloading of the other line 1-2, Fig. 4.

\subsection{Calculation of the Adjustment Factor $k_{Q}$ in Real Time Based on PMU Measurements}

DC model power flow calculation needs to be initially performed in order to perform the adaptation of the optimization algorithm to the nonlinear model. Power flow on line 1-2 (2) is $127,3 \mathrm{MW}$ according to the DC model power flows. According to Fig. 4, using a nonlinear AC model in the PSS/E software, power flow for line 1-2 (2) is 137,3 MW of active power and -19,6 MVAr of reactive power, which gives 138,7 MVA of apparent power.

Adjustment factor $k_{Q}$ for case of overloading line 1-2 (2) is calculated according to Eq. (10):

$k_{Q}=\frac{P_{1-2(2) D C}}{S_{1-2(2) R E A L}}=\frac{127,3 \mathrm{MW}}{138,7 \mathrm{MVA}}=0,92 \frac{\mathrm{MW}}{\mathrm{MVA}}$

Adjustment factor $k_{Q}$ of $0,92 \mathrm{MW} / \mathrm{MVA}$ is selected as input parameter in the overload optimization algorithm.

\subsection{Load Optimization with Selected Adjustment Factor}

According to input data of generation and load in each node, reactance of lines and transformers together with topology matrix, optimization algorithm as a solution gives loads which need to be disconnected in order to optimally mitigate overload of line 1-2 (2). Solution defines that load at busbar 6 of 11,2 MW and at busbar 11 of 3,5 MW, which makes total of $14,7 \mathrm{MW}$, needs to be disconnected in order to optimal mitigate overload of line 1-2 (2), Tab. 2. 

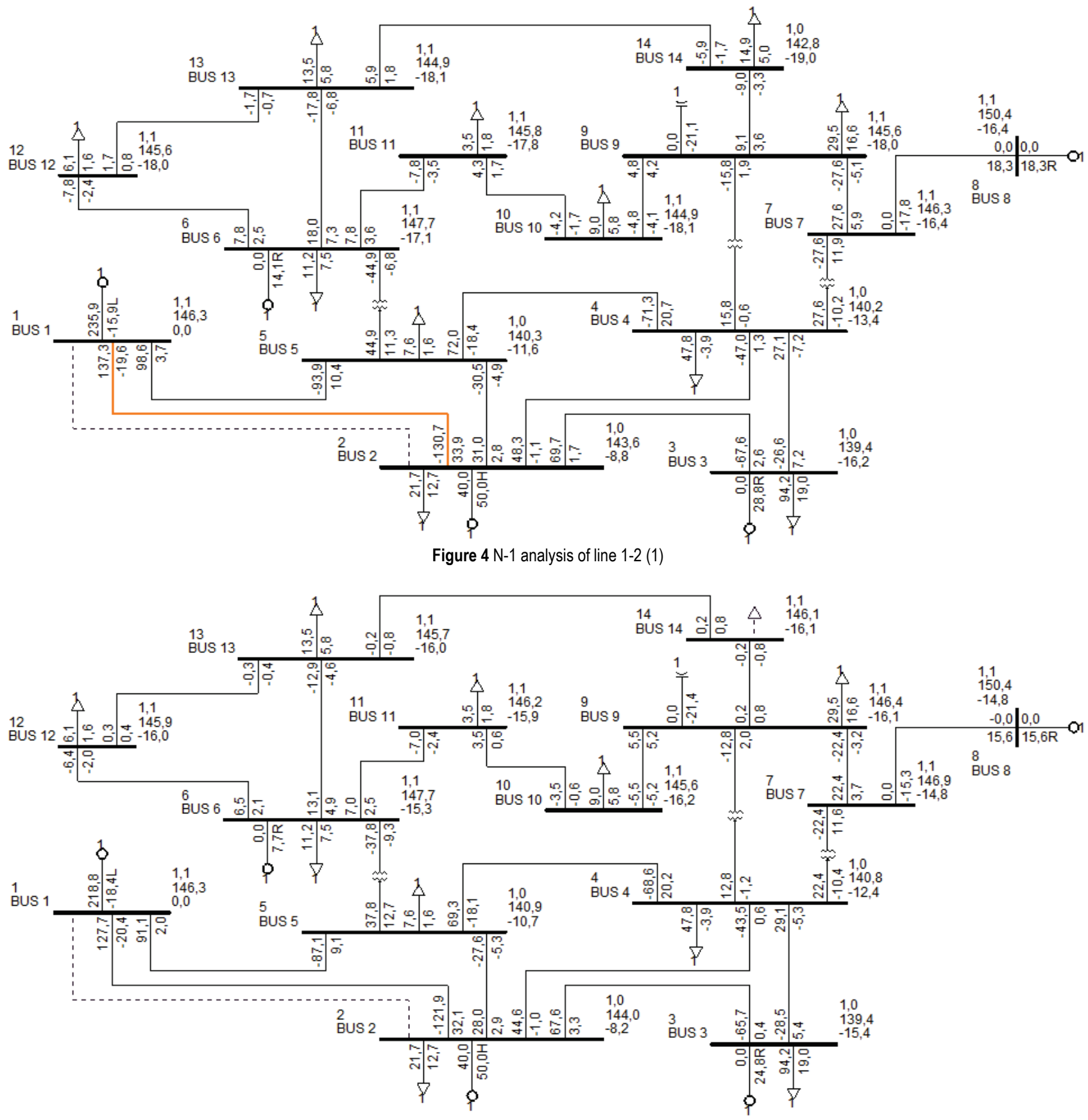

Figure 5 Checking optimization result on nonlinear model with implemented load supply priority

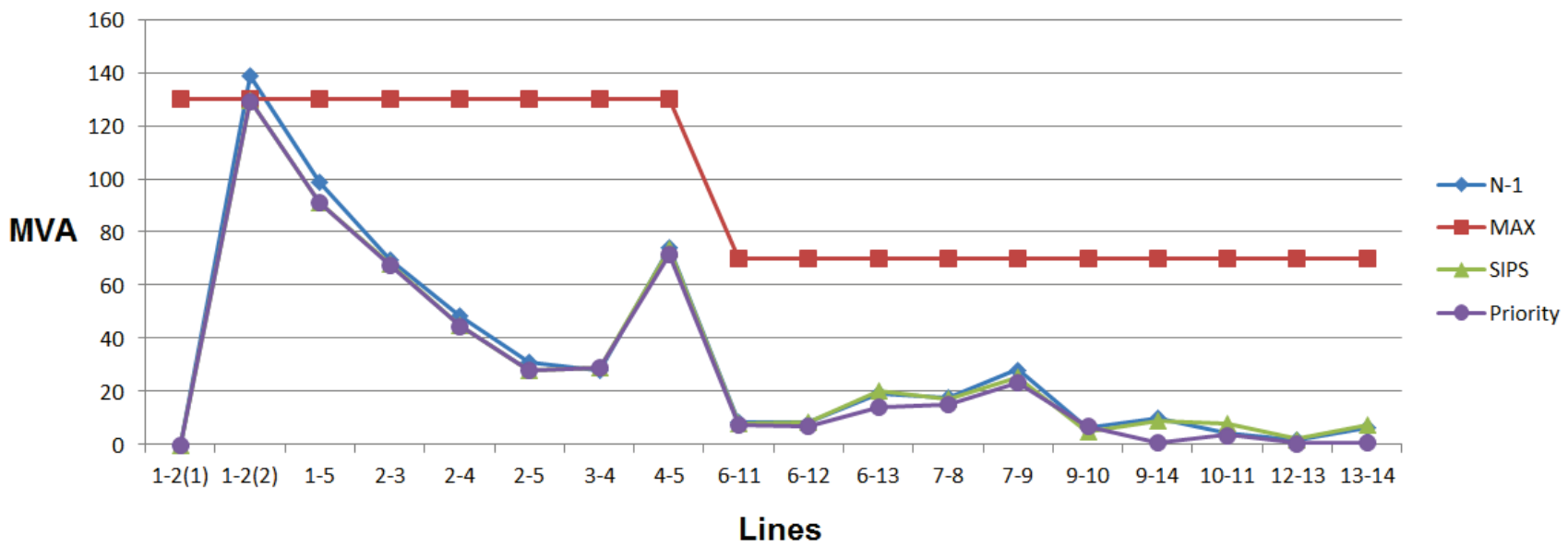

Figure 6 Line apparent power flow data for different activities 


\begin{tabular}{|c|c|c|c|}
\hline Busbar & $\begin{array}{c}\text { Load / } \\
\text { MW }\end{array}$ & \multicolumn{2}{|c|}{$\begin{array}{c}\text { Optimal load solution } \\
0 \text { - not connected, } \\
1 \text { - connected }\end{array}$} \\
\hline 1 & 0 & \multicolumn{2}{|c|}{0} \\
\hline 2 & 21,7 & \multicolumn{2}{|c|}{1} \\
\hline 3 & 94,2 & \multicolumn{2}{|c|}{1} \\
\hline 4 & 47,6 & \multicolumn{2}{|c|}{1} \\
\hline 5 & 7,6 & \multicolumn{2}{|c|}{1} \\
\hline 6 & 11,2 & \multicolumn{2}{|c|}{$\mathbf{0}$} \\
\hline 7 & 0 & \multicolumn{2}{|c|}{0} \\
\hline 8 & 0 & \multicolumn{2}{|c|}{0} \\
\hline 9 & 29,5 & \multicolumn{2}{|c|}{1} \\
\hline 10 & 9 & \multicolumn{2}{|c|}{1} \\
\hline 11 & 3,5 & \multicolumn{2}{|c|}{$\mathbf{0}$} \\
\hline 12 & 6,1 & \multicolumn{2}{|c|}{1} \\
\hline 13 & 13,5 & \multirow{2}{*}{\multicolumn{2}{|c|}{$\frac{1}{1}$}} \\
\hline 14 & 14,9 & 1 & \\
\hline \multicolumn{4}{|c|}{1 load before optimization / MW } \\
\hline \multicolumn{3}{|c|}{ Total optimized consumption / MW } & 244,3 \\
\hline \multicolumn{3}{|c|}{ Load that needs to be disconnected / MW } & 14,7 \\
\hline
\end{tabular}

\subsection{Checking Optimization Solution on Nonlinear Model}

Optimization algorithm solutions are checked by calculating nonlinear model power flows in the PSS/E. Outage of loads in busbars 6 and 11 was simulated. Power flow calculation results in active power of 128,2 MW and reactive power of -20,1 MVAr on line 1-2 (2), which gives apparent power of 129,77 MVA. Calculated apparent power is $99,82 \%$ of the assumed rated power. We can conclude that described optimization algorithm offered solution that successfully mitigates overload of line 1-2 (2) with extremely high accuracy.

\subsection{Implementing Load Supply Priority and Re-optimization}

Situation when some of the loads for different reasons must not be disconnected is predicted as part of described optimization algorithm. We can say that this kind of load has a supply priority over other loads. In order to check optimization algorithm, the next step proposes the originally chosen loads 6 and 11 as the load supply priorities. After re-optimization with given conditions of supply priority, the algorithm solution changes. The new solution defines load at busbar 14 of $14,9 \mathrm{MW}$ as one that needs to be disconnected in order to mitigate overload on line 1-2 (2), Tab. 3.

\subsection{Checking Optimization Solution on Nonlinear Model with Implemented Load Supply Priority}

Connected state of loads in busbars 6 and 11 and outage of load in busbar 14 were simulated using nonlinear model in PSS/E software. Power flow calculation results in 127,7 MW of active power and -20,4 MVAr of reactive power on line 1-2 (2), which gives apparent power of 129,32 MVA. Calculated apparent power represents $99,48 \%$ of assumed rated power, Fig. 5 . We can conclude that optimization algorithm with implemented load supply priority also offered solution that successfully mitigates overload of line 1-2 (2) with extremely high accuracy.
Table 3 Optimization results with implemented load supply priority

\begin{tabular}{|c|c|c|c|}
\hline Busbar & Load / MW & $\begin{array}{l}\text { Supply priority } \\
0 \text { - can be } \\
\text { disconnected } \\
1 \text { - cannot be } \\
\text { disconnected }\end{array}$ & $\begin{array}{l}\text { Optimal solution } \\
0 \text { - not connected, } \\
1 \text { - connected }\end{array}$ \\
\hline 1 & 0 & 0 & 0 \\
\hline 2 & 21,7 & 0 & 1 \\
\hline 3 & 94,2 & 0 & 1 \\
\hline 4 & 47,6 & 0 & 1 \\
\hline 5 & 7,6 & 0 & 1 \\
\hline 6 & 11,2 & 1 & 1 \\
\hline 7 & 0 & 0 & 0 \\
\hline 8 & 0 & 0 & 0 \\
\hline 9 & 29,5 & 0 & 1 \\
\hline 10 & 9 & 0 & 1 \\
\hline 11 & 3,5 & 1 & 1 \\
\hline 12 & 6,1 & 0 & 1 \\
\hline 13 & 13,5 & 0 & 1 \\
\hline 14 & 14,9 & $\mathbf{0}$ & $\mathbf{0}$ \\
\hline \multicolumn{3}{|c|}{ Total load before optimization / MW } & 259 \\
\hline \multicolumn{3}{|c|}{ Total optimized consumption / MW } & 244,1 \\
\hline \multicolumn{3}{|c|}{ Load that needs to be disconnected / MW } & 14,9 \\
\hline
\end{tabular}

\subsection{Comparison of Optimization Results}

Fig. 6 shows line apparent power flow data for N-1 analysis and optimization algorithm with and without supply priority in relation to the assumed rated power. Overload mitigation of line 1-2 (2) using described optimization algorithms can be easily detected reviewing given figure. Calculated values for line 1-2 (2) are shown in Tab. 4.

\begin{tabular}{|c|c|c|c|c|c|}
\hline Line & Unit & $S_{M A X}$ & $\begin{array}{l}\text { N-1 line } \\
1-2(1)\end{array}$ & $\begin{array}{l}\text { Optimal } \\
\text { SIPS }\end{array}$ & $\begin{array}{l}\text { Supply } \\
\text { priority }\end{array}$ \\
\hline \multirow{2}{*}{$1-2(2)$} & MVA & 130 & 138,69 & 129,77 & 129,32 \\
\hline & $\%$ & 100 & 106,69 & 99,82 & 99,48 \\
\hline
\end{tabular}

Fig. 7 shows busbar voltages for different activities from which is clear that implementation of described optimization algorithms does not endanger voltage conditions in the observed test system.

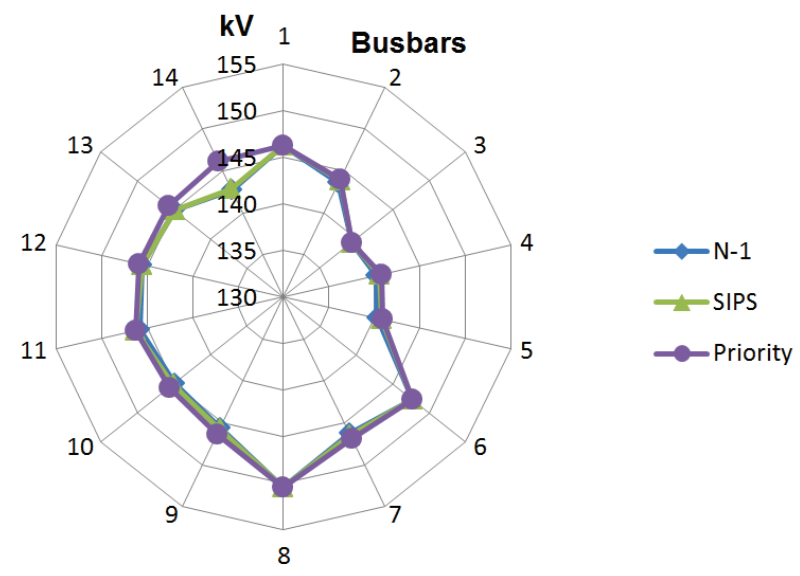

Figure 7 Busbar voltages for different activities

Duration of the described simulation was about $10 \mathrm{~ms}$ and optimal solution was reached within 14 iterations. Extremely fast calculation of optimal solution confirms possibility of application in SIPS. 


\section{APPLICATION ON THE REAL PART OF CROATIAN TRANSMISSION NETWORK}

Part of Croatian transmission network Istria is connected to the surrounding EPS through $220 \mathrm{kV}$ and 110 $\mathrm{kV}$ transmission lines (Fig. 8):

- 220 kV Plomin-Melina,

- 220 kV Plomin-Pehlin,

- 110 kV Plomin-Lovran-Matulji,

- $\quad 110$ kV Buje-Kopar.

Production capacity of Istria is defined by the centralized production of thermal power plant (TPP) Plomin consisting of two generators: Plomin 1 (115 MW) and Plomin $2(210 \mathrm{MW})$. Generator Plomin 1 is connected to a $110 \mathrm{kV}$ network and Plomin 2 to a $220 \mathrm{kV}$ network. The total production capacity of TPP Plomin 1 and 2 is 325 MW.

During the summer months most of consumption is concentrated in the east and west coast of Istria. The reason for this is the growing tourism development accompanied by the construction of large hotel chains. Summer peak loads of subsystem Istria is around 270 MW with a tendency of further growth.

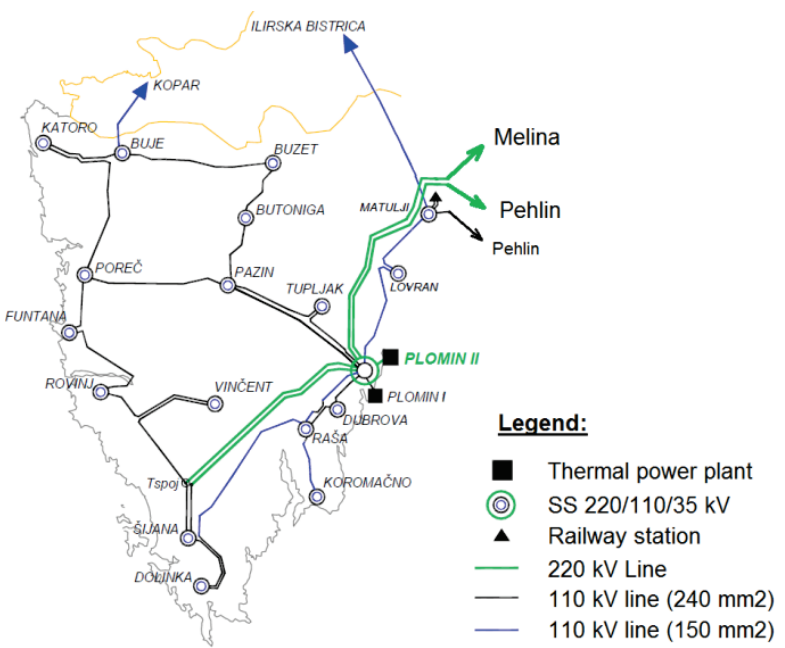

Figure 8 Part of Croatian power system Istria

Previous analyses [15] and [16] identified events that, during large summer bursts, bring the subsystem Istria to the state of the endangered condition. In the situation of unavailability of the double $220 \mathrm{kV}$ transmission line Plomin-Melina-Pehlin system security depends on the availability of TPP Plomin generators 1 and 2. Overloading of remaining connections Buje-Kopar and Plomin-LovranMatulji occurs in the case of unplanned unavailability of Plomin generators, which ultimately causes subsystem Istria blackout. This scenario happened in reality on 12 July 2012 due to the unplanned unavailability of TPP Plomin, which resulted in the complete supply disruption of subsystem Istria for a total duration of 26 minutes.

\subsection{Description of Analysed Scenarios}

Power subsystem Istria is modelled according to Fig. 8 in the software for power flow calculation PSS/E.

Model base scenario is defined according to the following:
- $220 \mathrm{kV}$ double line Plomin-Melina-Pehlin is disconnected,

- TPP Plomin is disconnected,

- peak loads are selected according to summer peak loads, Tab. 5.

Table 5 Selected busbar loads

\begin{tabular}{|c|c|c|c|c|}
\hline Busbar & Name & $P / \mathrm{MW}$ & $Q / \mathrm{MVAr}$ & $S / \mathrm{MVA}$ \\
\hline 1 & Matulji & 0 & 0 & 0 \\
\hline 2 & Kopar & 0 & 0 & 0 \\
\hline 3 & Lovran & 13,1 & 3,4 & 13,53 \\
\hline 4 & Plomin $110 \mathrm{~W} 1$ & 0 & 0 & 0 \\
\hline 5 & Plomin 220 & 0 & 0 & 0 \\
\hline 6 & Plomin $110 \mathrm{~W} 2$ & 0 & 0 & 0 \\
\hline 7 & Raša & 18,6 & 7,4 & 20,02 \\
\hline 8 & Koromačno & 5,6 & 1,1 & 5,71 \\
\hline 9 & Dolinka & 31,7 & 5,4 & 32,16 \\
\hline 10 & Šijana & 46,0 & 4,2 & 46,19 \\
\hline 11 & T-spoj & 0 & 0 & 0 \\
\hline 12 & Vinčent & 8,5 & 0,7 & 8,53 \\
\hline 13 & Rovinj & 25,6 & 6,5 & 26,41 \\
\hline 14 & Funtana & 21,7 & 4,8 & 22,22 \\
\hline 15 & Poreč & 32,5 & 4,4 & 32,80 \\
\hline 16 & Katoro & 12,2 & 2,9 & 12,54 \\
\hline 17 & Buje & 30,4 & 9,3 & 31,79 \\
\hline 18 & Buzet & 7,9 & 0,4 & 7,91 \\
\hline 19 & Butoniga & 2,6 & 0 & 2,60 \\
\hline 20 & Pazin & 10,8 & 2,5 & 11,09 \\
\hline 21 & Tupljak & 5,7 & 1,5 & 5,89 \\
\hline \multicolumn{2}{|c|}{ Active power / MW } & \multicolumn{3}{|c|}{272,9} \\
\hline \multicolumn{2}{|c|}{ Reactive power / MVAr } & \multicolumn{3}{|c|}{54,5} \\
\hline \multicolumn{2}{|c|}{ Apparent power / MVA } & \multicolumn{3}{|c|}{279,39} \\
\hline
\end{tabular}

For the described base scenario, subsystem Istria is powered by two lines: $110 \mathrm{kV}$ Matulji-Lovran-Plomin and $110 \mathrm{kV}$ Buje-Kopar. Matulji and Kopar are selected as external nodes. All other nodes within the subsystem are defined as internal. Matulji is chosen as the reference node. Rated power of connection lines Matulji-Lovran and BujeKopar are determined in accordance with the real state which in both cases is 89 MVA.

Tab. 6 gives power flow calculations for connection lines in nonlinear $\mathrm{AC}$ and linear $\mathrm{DC}$ model for the described scenario.

Table 6 Power flows before optimization Nonlinear AC model before optimization

\begin{tabular}{|c|c|c|c|c|c|}
\hline \multicolumn{6}{|c|}{ Nonlinear AC model before optimization } \\
\hline Line & $P / \mathrm{MW}$ & $Q / \mathrm{MVAr}$ & $S / \mathrm{MVA}$ & $S_{M A X} / \mathrm{MVA}$ & $\%$ \\
\hline $\begin{array}{l}\text { Matulji- } \\
\text { Lovran }\end{array}$ & 161,3 & 51 & 169,2 & 89 & 190,1 \\
\hline $\begin{array}{l}\text { Buje- } \\
\text { Kopar }\end{array}$ & 141,9 & 57,2 & 153 & 89 & 171,9 \\
\hline \multicolumn{6}{|c|}{ Linear DC model before optimization } \\
\hline \multicolumn{3}{|c|}{ Line } & \multicolumn{3}{|c|}{$P / \mathrm{MW}$} \\
\hline \multicolumn{3}{|c|}{ Matulji-Lovran } & \multicolumn{3}{|c|}{148,1} \\
\hline \multicolumn{3}{|c|}{ Buje-Kopar } & \multicolumn{3}{|c|}{131,3} \\
\hline
\end{tabular}

\subsection{Calculation of the Adjustment Factor $k_{Q}$}

According to Tab. 6, DC model power flow calculation gives active power of 148,1 MW on line Matulji-Lovran and 131,3 MW on line Buje-Kopar. AC model power flow calculation gives apparent power of 169,2 MVA for line Matulji-Lovran and 153 MVA for line Buje-Kopar.

Adjustment factor $k_{Q}$ for case of overloading lines Matulji-Lovran and Buje-Kopar is calculated according to Eq. (11) and (12): 


$$
\begin{aligned}
& k_{Q 1-3}=\frac{P_{1-3 D C}}{S_{1-3 R E A L}}=\frac{148,1 \mathrm{MW}}{169,2 \mathrm{MVA}}=0,86 \frac{\mathrm{MW}}{\mathrm{MVA}} \\
& k_{Q_{2-17}}=\frac{P_{1-17 D C}}{S_{1-17 R E A L}}=\frac{131,3 \mathrm{MW}}{153 \mathrm{MVA}}=0,86 \frac{\mathrm{MW}}{\mathrm{MVA}}
\end{aligned}
$$

Adjustment factor $k_{Q}$ of $0.86 \mathrm{MW} / \mathrm{MVA}$ is selected as input parameter in the overload optimization algorithm for case of overloading lines Matulji-Lovran and Buje-Kopar.

\subsection{Optimization Results}

Tab. 7 shows output results of optimization algorithm according to the defined scenario.

Table 7 Optimization results for defined scenario

\begin{tabular}{|c|c|}
\hline Total load before optimization & 279,39 MVA \\
\hline Loads that need to be disconnected & $3,8,10,14,16,18,20$ \\
\hline Total load that needs to be disconnected & 119,19 MVA \\
\hline Total optimized consumption & 160,20 MVA \\
\hline
\end{tabular}

Tab. 8 gives power flows for connection lines MatuljiLovran and Buje-Kopar after implementing optimization algorithm. Overloading of connection lines has been mitigated and the high availability of transmission power is achieved. Power flow of 97,1 \% was achieved for line Matulji-Lovran and 92,7 \% for line Buje-Kopar.

Table 8 Power flows for connection lines after optimization

\begin{tabular}{|c|c|c|c|c|c|}
\hline \multicolumn{7}{|c|}{ Nonlinear AC model after optimization } \\
\hline Line & $P / \mathrm{MW}$ & $Q / \mathrm{MVAr}$ & $S /$ MVA & $S_{\text {MAX }} /$ MVA & $\%$ \\
\hline $\begin{array}{c}\text { Matulji- } \\
\text { Lovran }\end{array}$ & 84,6 & 17,6 & 86,4 & 89 & $\mathbf{9 7 , 1}$ \\
\hline $\begin{array}{c}\text { Buje- } \\
\text { Kopar }\end{array}$ & 79,0 & 23,8 & 82,5 & 89 & $\mathbf{9 2 , 7}$ \\
\hline
\end{tabular}

In the study of optimization algorithm on real part of Croatian transmission network, supply priority was not given to individual nodes. In further development of optimization algorithm, in cooperation with distribution system operator in the observed network part, it will be necessary to define criteria for selecting importance of consumers of subsystem Istria, according to which supply priorities of certain nodes should be defined.

\section{CONCLUSION}

Optimal overload mitigation algorithm based on the DC model and synchronized measurements is given in this paper. Calculation of power flows according to DC network model is characterized by simplicity and speed. There are no convergence problems as in other non-linear models making it suitable for use in time-limited applications such as WAMPAC systems. Synchronized phasor measurement technology allows you to collect realtime network data and provide fast and reliable performance of SIPS.

Universality of described algorithm was tested on the IEEE 14 busbar test system. From the analyses carried out we can conclude that described optimization algorithm offered results that successfully mitigate overloading of test system with extraordinary accuracy.

Algorithm applicability on the real model of EPS has been shown by checking algorithm on subsystem Istria.
Analyses showed that it has been successful in overload mitigation while simultaneously utilizing the available transmission power of connection lines. It is therefore concluded that the described algorithm can be used in further development of SIPS in subsystem Istria.

In further development, it is necessary to analyse possibility of applying optimization algorithm to subsystems with a high share of reactive power, as well as to subsystems where there is electricity production at certain nodes.

\section{REFERENCES}

[1] Zhang, Z., Chen, W., \& Zhang, Z. (2015). Research on the relay protection system of micro-grid. Technical Gazette, 22(1), 51-59. https://doi.org/10.17559/TV-20150210221236

[2] Zbunjak, Z. \& Kuzle, I. (2013). Advanced Control and System Integrity Protection Schemes of Croatian Power Transmission Network with Integrated Renewable Energy Sources. Eurocon 2013, Zagreb, 706-711. https://doi.org/10.1109/EUROCON.2013.6625060

[3] Phadke, A. G. \& Thorp, J. S. (2008). Synchronized Phasor Measurements and Their Applications. New York, NY: Springer.

[4] Kirincic, V., Skok, S., \& Frankovic, D. (2016). A noninvasive inclusion of synchrophasors in the power system state estimation. Technical Gazette, 23(5), 1457 1462. https://doi.org/10.17559/TV-20150118204850

[5] Martin, K. E. et al. (2008). Exploring the IEEE Standard C37.118-2005 Synchrophasors for Power Systems. IEEE Transactions on Power Delivery, 23(4), 1805-1811. https://doi.org/10.1109/TPWRD.2007.916092

[6] Terzija, V., Valverde, G., Cai, D., Regulski, P., Madani, V., Fitch, J., Skok, S., Begovic, M., \& Phadke, A. (2011). Wide Area Monitoring, Protection, and Control of Future Electric Power Networks. Proceedings of the IEEE, 99(1), 80-93. https://doi.org/10.1016/j.ifacol.2016.10.724

[7] Anderson, P. M. \& LeReverend, B. K. (1996). Industry Experience with Special Protection Schemes. IEEE Transactions on Power Systems, 11(3), 1166-1179. https://doi.org/10.1109/59.535588

[8] Madani, V., Novosel, D., Horowitz, S., Adamiak, M., Amantegui, J., Karlsson, D., Imai, S., \& Apostolov, A. (2010). IEEE PSRC Report on Global Industry Experiences with System Integrity Protection Schemes (SIPS). IEEE Transactions on Power Delivery, 25(4), 2143-2155. https://doi.org/10.1109/TPWRD.2010.2046917

[9] Zbunjak, Z. \& Kuzle, I. (2011). Possible savings in electricity transmission using wide area monitoring technologies in Croatian power transmission network. $8^{\text {th }}$ International Conference on the European Energy Market (EEM11), Zagreb, 495-500. https://doi.org/10.1109/EEM.2011.5953062

[10] Quiros-Tortos, J., Wall, P., \& Terzija, V. (2016). Reducing excessive standing phase angle differences: A new approach based on $\mathrm{OPF}$ and wide area measurements. International Journal of Electrical Power \& Energy Systems, 78, 13-21. https://doi.org/10.1016/j.jiepes.2015.11.078

[11] Cai, D., Wall, P., Osborne, M., \& Terzija, V. (2016). Roadmap for the deployment of WAMPAC in the future GB power system. IET Generation, Transmission \& Distribution, 10(7), 1553-1562. https://doi.org/10.1049/iet-gtd.2015.0582

[12] Wikipedia, Integer programming. https://en.wikipedia.org/ wiki/Integer programming (Accessed 2018-07-15)

[13] Purchala, K. (2005). Modelling and analysis of technoeconomic interactions in meshed high voltage grids 
exhibiting congestion. $\mathrm{PhD}$ thesis, University of Leuven (K.U. Leuven), (CD edition)

[14] University Washington, Power system test case archive. $\mathrm{http} / / /$ www.ee.washington.edu/research/pstca/pf14/pg_tca1 4bus.htm (Accessed 2017-09-23)

[15] Kotorac, D., Zbunjak, Z., Valentić, V., Sokolić, L., \& Šumberac, B. (2013). Analysis of application possibilities of advanced control system on the electrical power subsystem of Istria. $11^{\text {th }}$ HRO CIGRÉ Session, Cavtat, (CD edition)

[16] Kotorac, D., Andrić, A., Frlan, K., Sokolić, L., \& Zbunjak, Z. (2016). Activities for preventing EPS blackouts in the Istria region. $12^{\text {th }}$ symposium on power system management, Split, (CD edition)

\section{Contact information:}

\section{Zoran ZBUNJAK, M. E.E}

Croatian Transmission System Operator Ltd.

Transmission Area Rijeka

Marinčićeva ulica 3, 51211 Matulji, Croatia

zoran.zbunjak@hops.hr

\section{Igor KUZLE, PhD, E.E}

University of Zagreb

Faculty of Electrical Engineering and Computing

Unska 3, 10000 Zagreb, Croatia

igor.kuzle@fer.hr

\section{Dino MAĐAR, M. E.E.}

Croatian Transmission System Operator Ltd.

Transmission Area Rijeka

Marinčićeva ulica 3, 51211 Matulji, Croatia

dino.madar@hops.hr 